\title{
Bone morphogenetic protein 4 stimulates neuronal differentiation of neuronal stem cells through the ERK pathway
}

\author{
Byoung-San Moon ${ }^{1}$, Ju-Yong Yoon ${ }^{1}$, \\ Mi-Yeon Kim', Sang-Hun Lee ${ }^{2}$, \\ Thomas Choi ${ }^{1 *}$ and Kang-Yell Choi ${ }^{1,2,3}$ \\ ${ }^{1}$ Department of Biotechnology and \\ Protein Network Research Center \\ Yonsei University \\ Seoul 120-752, Korea \\ ${ }^{2}$ Department of Biochemistry \\ College of Medicine \\ Hanyang University \\ Seoul 133-791, Korea \\ ${ }^{3}$ Corresponding author: Tel, 82-2-2123-2887; \\ Fax, 82-2-362-7265; E-mail, kychoi@yonsei.ac.kr \\ *Present address; College of Letters and Science \\ University of California, Berkeley, CA, USA \\ DOI 10.3858/emm.2009.41.2.014
}

Accepted 6 November 2008

Abbreviations: bFGF, basic fibroblast growth factor; BMP, bone morphogenetic protein; $\mathrm{CP}$, cortical plate; GSK3 $\beta$, glycogen synthase kinase 3 $\beta$; IMZ, intermediate zone; NSC, neural stem cell; SVZ, subventricular zone; Tuj1, $\beta$-tubulin type III; VPA, valproic acid

\begin{abstract}
Bone morphogenic protein 4 (BMP4), a member of the TGF- $\beta$ superfamily, induced neural differentiation of neural stem cells (NSCs) grown in a medium containing basic fibroblast growth factor (bFGF). The Ras protein level and the activities of the downstream ERKs were increased by transfection of BMP4 or treatment with recombinant BMP4. The effects of BMP4, including activation of the Ras-ERK pathway and induction of the neuron marker $\beta$-tubulin type III (Tuj1), were blocked by co-treatment of the BMP4 antagonist, noggin. The roles of the Ras-ERK pathway in neuronal differentiation by BMP4 were revealed by measuring the effect of the ERK pathway inhibition by dominant negative Ras or PD98059, the MEK specific inhibitor. BMP4 is a transcriptional target of Wnt/ $\beta$-catenin signaling, and both the mRNA and protein levels of BMP4 were increased by treatment of valproic acid (VPA), a chemical inhibitor of glycogen synthase kinase $3 \beta$ (GSK3 $\beta$ ) activating the Wnt/ $\beta$-catenin pathway. The BMP4- mimicking effects of VPA, activation of the Ras-ERK path-
\end{abstract}

way and induction of Tuj1, also were blocked by noggin. These results indicate the potential therapeutic usage of VPA as a replacement for BMP4.

Keywords: bone morphogenetic protein 4; cell differentiation; extracellular signal-regulated MAP kinases; neurons; stem cells; valproic acid

\section{Introduction}

Understanding the mechanism of the differentiation of neuronal stem cells (NSCs) in the central nervous system (CNS) is important in the field of regenerative medicine. The expressions of the extracellular secretory factors play significant roles in the differentiation of multipotent stem cells (Panchision and McKay, 2002; Jung et al., 2007).

Bone morphogenetic proteins (BMPs), members of the TGF- $\beta$ superfamily, are extracellular secretory proteins effecting neuronal differentiation (Varley and Maxwell, 1996; Li et al., 1998). BMP4 is expressed in the embryonic cortex (Furuta et al., 1997; Li et al., 1998), indicating potential roles of BMP4 in the differentiation of NSCs. BMP4 is involved in differentiation of NSCs to smooth muscle cells or Schwann cells (Mujtaba et al., 1998; Molne et al., 2000; Panchision et al., 2001). BMP4 also promotes neuronal and glial differentiations of NSCs in the neocortical ventricular zone (Gross et al., 1996; Varley and Maxwell, 1996; Li et al., 1998; $\mathrm{Xu}$ et al., 2002). BMP4's neuronal differentiation of NSCs is known to be mediated via the Smad and JNK pathways (Goswami et al., 2001). Involvement of several signaling pathways such as $W n t / \beta$ catenin, Phosphoinositide-3 kinase (PI-3K), p38, ERK and JNK in the proliferation and differentiation of mouse embryonic stem cells was indicated without characterization of mechanisms (Lin et al., 2008). However, involvement of other signaling pathway (s) in BMP4's neuronal differentiation of NSCs remains unclear.

In the present study, we investigated the role of BMP4 in neuronal differentiation of NSCs related with the ERK and Wnt/ $\beta$-catenin pathways which known to involves proliferation and differentiation of various types of cells (Mohan et al., 1998; Goswami et al., 2001; Kuroda et al., 2005; Zhou et al., 2007). BMP4 induced neuronal differentiation, inhibiting proliferation, by overcoming the effects of the anti-differentiation factor bFGF in the NSCs. 
The roles of BMP4 were further confirmed by the blocking of its effects by co-treatment of the BMP4 antagonist, noggin. The BMP4 activated the ERKs in the NSCs grown in a medium containing bFGF. Interestingly, the Ras level also was increased by the BMP4 treatment under the condition of significantly suppressed epidermal growth factor (EGFR) (Lillien and Raphael, 2000; Garcion et al., 2004). Regulation of Ras protein levels also has been identified in several recent studies using different types of cells, including primary hepatocytes (Park et al., 2006; Jeon et al., 2007), and $\beta$-catenin has been identified as a mediator in Ras protein regulation (Park et al., 2006; Jeon et al., 2007).

Valproic acid (VPA, 2-propyl-pentanoic acid) is a mood-stabilizing and epilepsy-treatment drug that has been administered over several decades (Perucca, 2002). VPA is known to directly (Chen et al., 1999; Grimes and Jope, 2001) or indirectly (Gould and Manji, 2002; Gould et al., 2004) inhibit the activity of glycogen synthase kinase $3 \beta$ (GSK3 $\beta$ ), and activates $\mathrm{Wnt} / \beta$-catenin signaling. VPA has been shown to stabilize $\beta$-catenin in NSCs grown in bFGF-containing media and to induce BMP4,

A
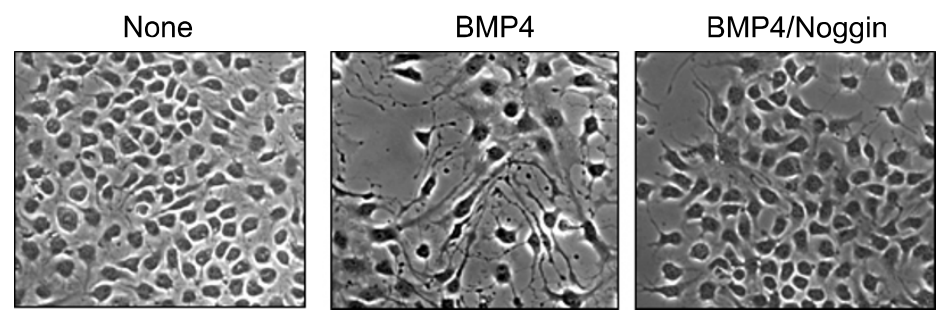

B

C
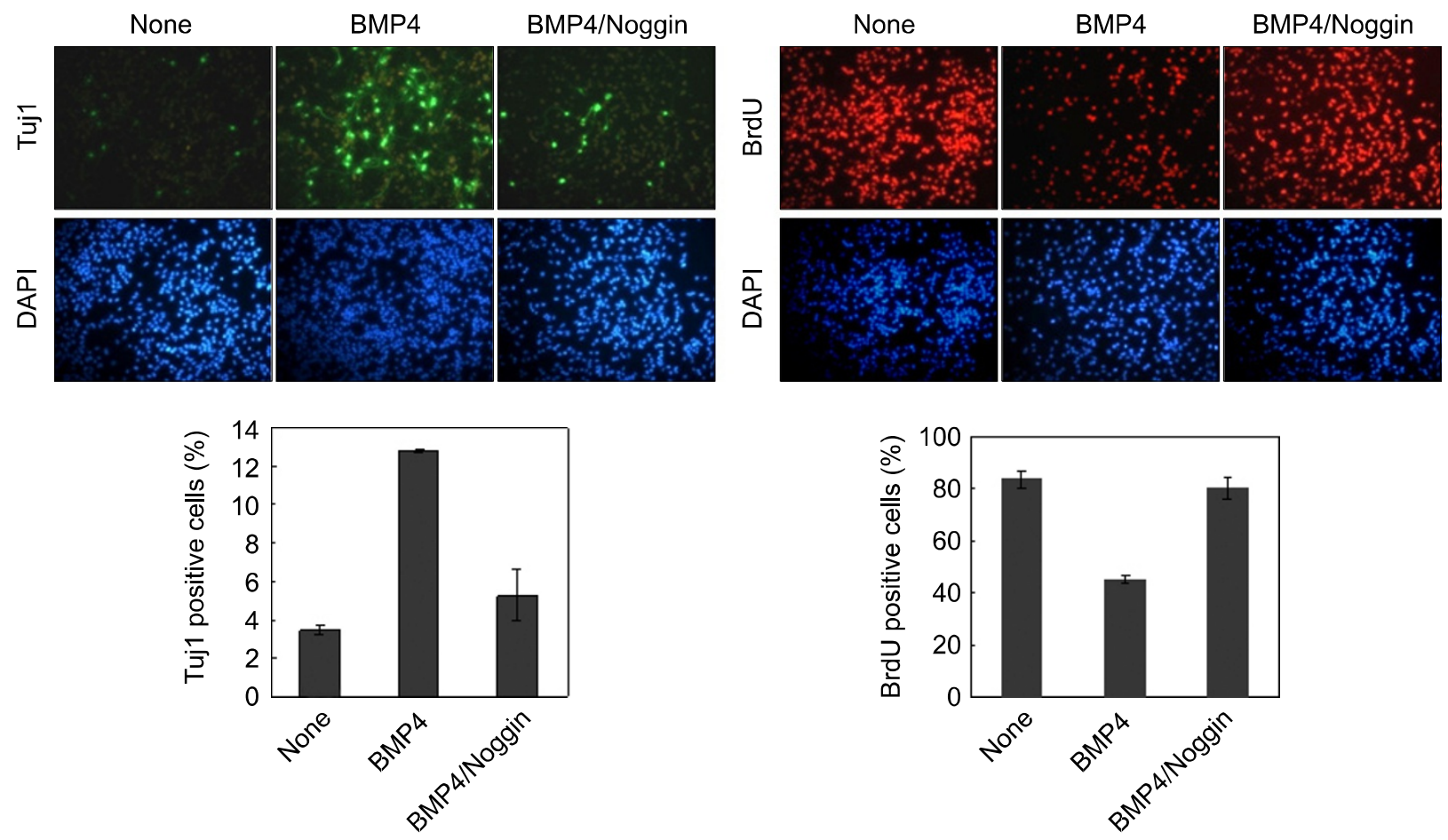

Figure 1. Effect of BMP4 on differentiation and proliferation of NSCs. NSCs that were grown in the N2 medium containing bFGF (10 ng/ml) were treated with $20 \mathrm{ng} / \mathrm{ml}$ of BMP4 for $48 \mathrm{~h}$. One case required noggin was co-treated with BMP4 (150 ng/ml). (A) Micrographs were taken, using a phase-contrast microscope at $400 \times$ magnification. (B-C) The cells were processed for immunofluorescent labeling of Tuj1 (green) and BrdU (red). The nuclei were counterstained with DAPI (blue). All of the images taken of the cells labeled with fluorescent chemicals were magnified $200 \times$ using a fluorescent microscope. The percentages of BrdU-positive and Tuj1-positive cells were determined. The error bars indicate the standard deviations of three independent experiments. The data represent the mean $\pm \mathrm{SD}$ of three separate experiments. 
retaining the Tcf/ $\beta$-catenin binding site in its promoter (Baker et al., 1999; Kim et al., 2002). BMP4 induction by VPA occurs at a transcription level, as shown by increments of levels both of mRNA and protein. We determined that VPA mimics the effects of BMP4, such as increases in Ras, activation of ERKs, suppression of EGFR, and induction of differentiation. The BMP4-mimicking effects of VPA could be achieved via the induction of BMP4, which was confirmed by blockages of the VPA effects by co-treatment of noggin. The roles of the Ras-ERK pathway in the activation of differentiation and inhibition of proliferation were further confirmed by measurement of the effects of ERK pathway inhibition. Finally, we provide in vivo data on the BMP4 induction, the Ras increase, and the subsequent activation of differentiation and inhibition of NSC proliferation in the cerebral cortex by measuring the effects of the intravenous application of VPA to the E13.5 rat embryo. Overall, BMP4 induced differentiation of NSCs via the Ras-ERK pathway, by overcoming the anti-differentiative effect of bFGF. The BMP4-mimicking effects of VPA indicate that VPA can potentially be used as a BMP4 replacement in therapeutic roles such as inhibition of the growth of brain-tumor-initiating cells (Piccirillo et al., 2006).

\section{Results}

\section{BMP4 induces differentiation of NSCs by overcoming mitogenic effect of bFGF}

To understand the roles of BMP4 in neuronal diffe- rentiation, we measured the effect of recombinant BMP4 on the NSCs. The NSCs did not differentiate when they were grown in the medium containing bFGF, a mitogen that inhibits differentiation of NSCs (Gage, 2000) (Figure 1A). By contrast, the NSCs underwent morphological differentiation when the cells were treated with BMP4, which differentiation was inhibited by co-treatment of the BMP4 antagonist, noggin (Figure 1A). The differentiation of NSCs by BMP4 and the blocking of the effect by noggin were confirmed by immunocytochemical analysis using the neuronal marker Tuj1. The Tuj1-positive cells were increased in abundance (from 3.4 to $12.8 \%$ ) by the BMP4 treatment (Figure 1B). However, the BrdU-positive proliferating cells were decreased (from 83 to $45 \%$ ) (Figure 1C). The cell cycle inhibitory effect of BMP4 has been reported previously ( $\mathrm{Li}$ et al., 1998). Overall, BMP4 stimulated differentiation and inhibited proliferation of the NSCs that were grown in the bFGF-containing medium.

\section{BMP4 activates ERK pathway and induces differentiation via up-regulation of Ras in NSCs}

The Ras-ERK pathway is a major signaling route involving the regulation of neuronal differentiation (Lewis et al., 1998; Cobb, 1999; Vaudry et al., 2002; Kato et al., 2005). To identify involvement of the Ras-ERK pathway in the neuronal differentiation of NSCs, we monitored the effects of BMP4 overexpression in the regulation of the ERK pathway. The ERK activities were markedly increased with simultaneous induction of Tuj1 (Figure 2A).
A

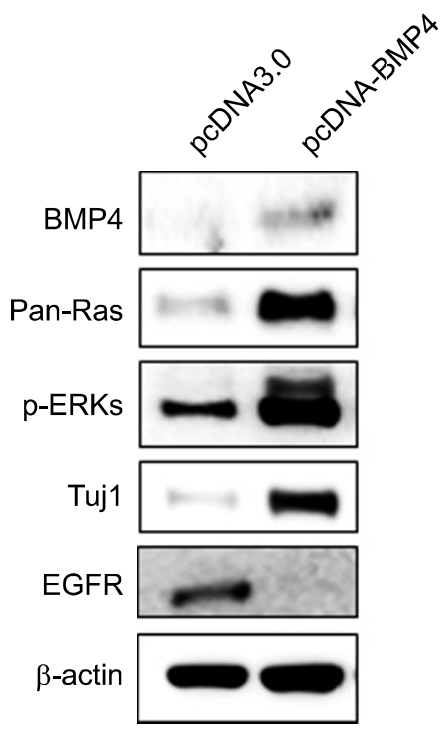

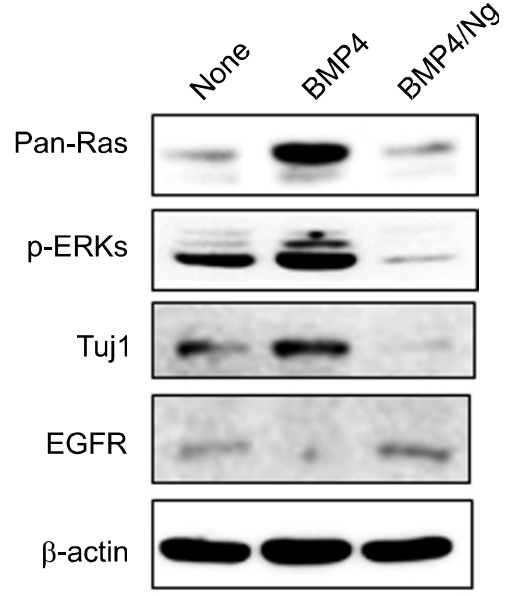

Figure 2. Effects of BMP4 on regulations of Ras-ERK pathway and Tuj1 in NSCs. (A-B) NSCs were grown in the bFGF-containing medium (10 ng/ml). (A) The cells were transfected with $2 \mu \mathrm{g}$ of pcDNA3.0 or pcDNA3.0-BMP4 in a $60 \mathrm{~mm}$ dish. (B) The cells were treated with $20 \mathrm{ng} / \mathrm{ml}$ of recombinant BMP4 together with or without $150 \mathrm{ng} / \mathrm{ml}$ of recombinant noggin. 
Interestingly, we also observed significant up-regulation of the level of Ras, which functions at the upstream of ERK (Figure 2A). Contrastingly, EGFR, a further upstream component of the Ras-ERK pathway, was suppressed by BMP4 overexpression (Figure 2A). The supression of EGFR by BMP4 in NSC also has been identified previously by researchers (Lillien and Raphael, 2000; Garcion et al., 2004). All of the effects of BMP4, the increased Ras level, the activation of ERK, induction of Tuj1 and suppression of EGFR, were observed also in the NSCs treated with purified recombinant BMP4 (Figure 2B). Moreover, the BMP4 effects were simultaneously blocked by antagonizing BMP4 activation induced by co-treatment of noggin (Figure 2B). Therefore, the BMP4 activated the Ras-ERK pathway and Tuj1, via extracellular signaling of the secreted BMP4. To test the involvement of the Ras-ERK pathway in differentiation and anti-proliferation of NSCs, we tested the effects of the MEK inhibitor PD98059. Both stimulation of differentiation and inhibition of proliferation by
BMP4 were significantly blocked by treatment of both BMP4 and PD98059 (Figure 3A and B). That is to say, differentiation and anti-proliferation of NSCs result at least partly from the activation of the ERK pathway.

\section{VPA activates Ras-ERK pathway and induces neuronal differentiation through BMP4 induction by activation of $\beta$-catenin}

BMP4 has previously been identified as one of the transcription targets of the $\mathrm{Wnt} / \beta$-catenin pathway (Baker et al., 1999). The mRNA level of BMP4 was significantly increased by treatment with VPA, a GSK3 $\beta$-inhibitor-activating $\beta$-catenin (Chen et al., 1999; Grimes and Jope, 2001) (Figure 4A). By contrast, the mRNA level of EGFR was decreased by VPA treatment (Figure 4A; lower panel). The protein level of BMP4 as well as $\beta$-catenin also was increased by VPA treatment (Figure 4B). Moreover, all of the effects of BMP4, Ras level increases, ERK activities, Tuj1 induction, and EGFR
A
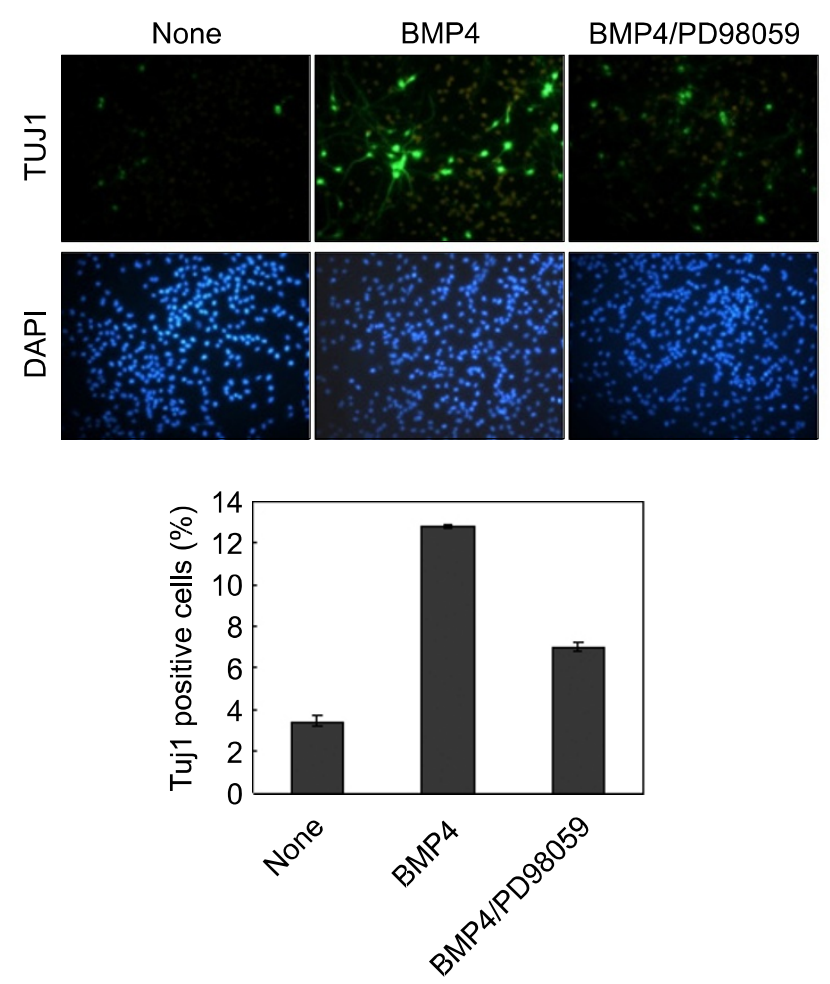

B
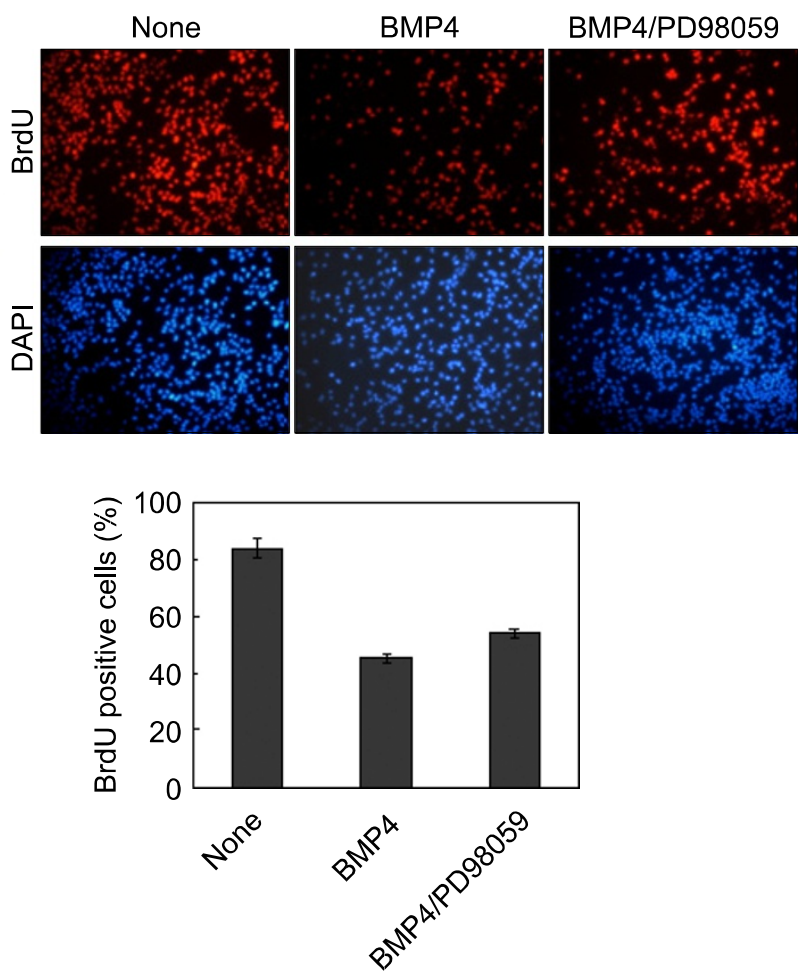

Figure 3. Effects of PD98059 on stimulation of differentiation and on inhibition of proliferation of NSCs by BMP4. NSCs were grown in the N2 medium containing bFGF $(10 \mathrm{ng} / \mathrm{ml})$, and treated with $20 \mathrm{ng} / \mathrm{ml}$ of BMP4 for $48 \mathrm{~h}$ together with or without $20 \mu \mathrm{g} / \mathrm{ml}$ of PD98059. The cells were processed for immunofluorescent labeling of Tuj1 (green) (A) and BrdU (red) (B). The nuclei were counterstained with DAPI (blue). All of the images taken of the cells labeled with fluorescent chemicals were magnified $\times 200$ using a fluorescent microscope. The percentages of BrdU-positive and Tuj1-positive cells were determined. The error bars indicate the standard deviations of three independent experiments. The data represent the mean \pm SD of three separate experiments. 
suppression, were observed when the NSCs were treated with VPA (Figure 4B). Thus it was confirmed that VPA, transcriptionally inducing BMP4, mimics the effects of BMP in NSCs.

To identify the role of BMP4 in the VPA-induced activation of the Ras-ERK pathway and Tuj1 induction, we measured the effects of noggin. Here, the morphological differentiation of NSCs by VPA was abolished by co-treatment of noggin (Figure 4C). Moreover, the VPA effects, including Ras level increase, activation of ERK, EGFR suprpession, and induction of Tuj1, were simultaneously blocked by co-treatment of noggin (Figure 4D). The VPA effects were acquired by Tcf/ $\beta$-catenin-mediated transcriptional activation via $\mathrm{Wnt} / \beta$ - catenin signaling ( $\mathrm{He}$ et al., 1998; Leng et al., 2008), as indicated by the blocking of all of the VPA effects by transfection of dominant negative Tcf (dnTcf) (Figure 4E). Overall, VPA activated the Ras-ERK pathway through BMP4 induction via Tcf/ $\beta$-catenin-mediated transcription. Finally, we investigated the role of the Ras-ERK pathway in VPA-induced differentiation by measuring the effect of dominant negative Ras (dnRas) in Tuj1 induction (Figure 4F). Here, we observed that Tuj1 induction and ERK activation were abolished by overexpression of dnRas (Figure 4F). Both VPA and BMP4 induced neural differentiation through the activation of the Ras-ERK pathway in the proliferative NSCs grown in the bFGF medium.
A

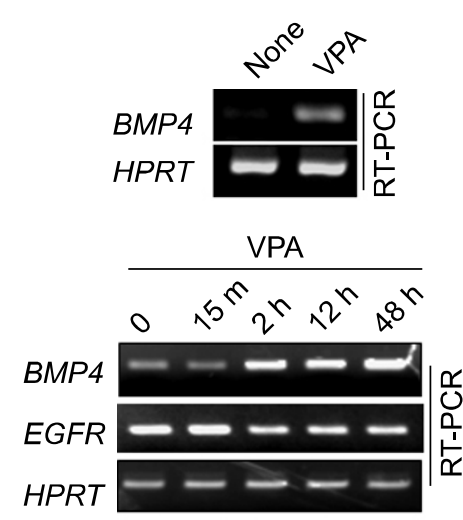

B

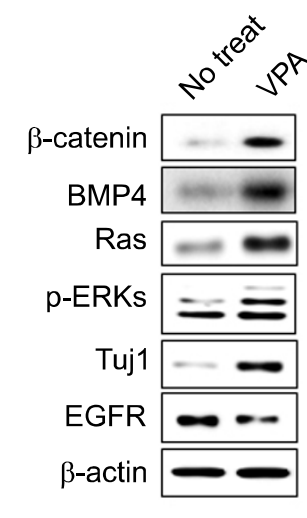

C

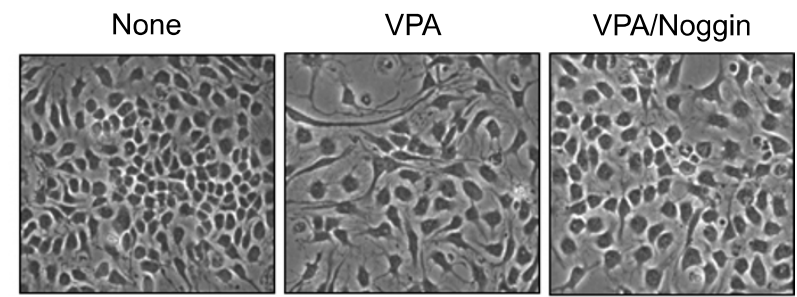

D

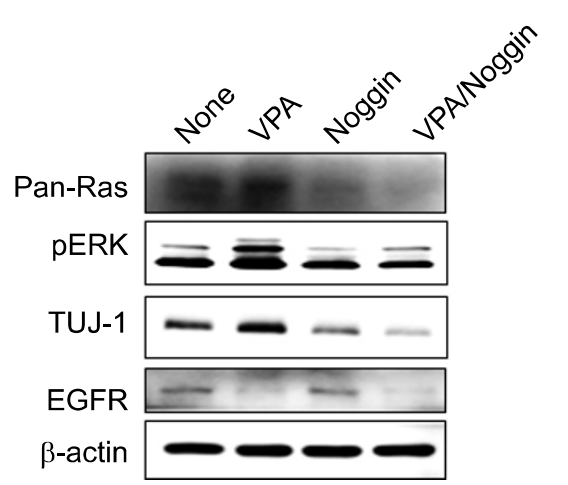

E

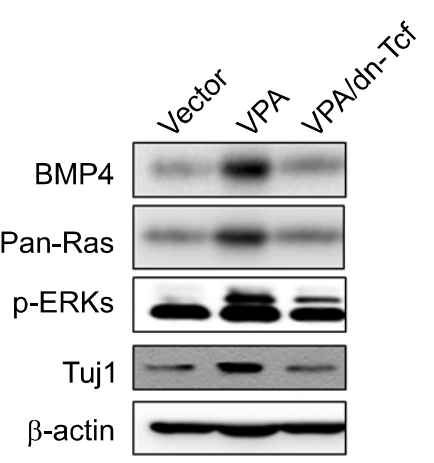

$\mathbf{F}$

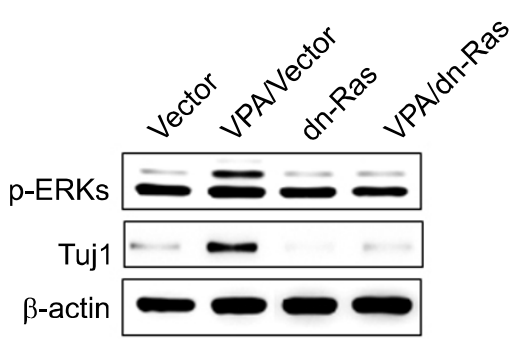

Figure 4. Effects of VPA on neural differentiation and activation of Ras-ERK pathway in NSCs. (A) NSCs were either not treated or treated with $1 \mathrm{mM}$ VPA for different time periods $(0,15 \mathrm{~min}, 2 \mathrm{~h}, 12 \mathrm{~h}$ or $48 \mathrm{~h})$. The mRNA level of the BMP4, EGFR or HPRT were measured by RT-PCR, followed by agarose gel electrophoresis. (B) NSCs were either not treated or treated with $1 \mathrm{mM}$ VPA for $48 \mathrm{~h}$, and the levels of $\beta$-catenin, BMP4, pan-Ras, $p$-ERK, Tuj1, EGFR or $\beta$-actin were monitored by immune blot analyses. (C-D) NSCs were grown in the bFGF-containing medium (10 ng/ml). The cells were treated with $1 \mathrm{mM}$ VPA for $48 \mathrm{~h}$, together with or without $150 \mathrm{ng} / \mathrm{ml}$ of recombinant noggin. (C) Micrographs were taken using an ECLIPSE TE2000-U fluorescent microscope at $\times 400$ magnification. (D) Pan-Ras, p-ERK, Tuj1, EGFR or $\beta$-actin were monitored by immune blot analyses. (E-F) NSCs were transfected with $2 \mu \mathrm{g}$ of pcDNA3.0, dn-Tcf-pcDNA3.0, or dn-Ras in a $60 \mathrm{~mm}$ dish, and treated or non-treated with $1 \mathrm{mM}$ VPA in the presence of bFGF (10 ng/ml) for $48 \mathrm{~h}$. The levels of BMP4, pan-Ras, p-ERK, Tuj1 or $\beta$-actin were determined also by immunoblot analyses. 


\section{VPA increases levels of BMP4 and Ras, and induces differentiation of NSCs in embryonic cortex of developing Rat brain}

To understand the physiological relevance of the VPA-mediated biochemical changes in vivo, we examined the E15.5 rat embryo in order to observe the effects of VPA administration on differentiation in the cerebral cortex. In the absence of VPA administration, the $D A B$ staining patterns for Tuj 1 and PCNA were distinct, as also observed in a previous study (Tanriover et al., 2005). In the PBSadministered control animals, Tuj1 staining was predominantly localized to the cortical plate (CP) area, where differentiated neuronal cells reside (Figure 5A; upper left panel). However, the PCNA staining was mostly localized to the subventricular zone (SVZ) and intermediate zone (IMZ), where
progenitors/NSCs reside (Figure 5A; middle left panel). Tuj1 staining was increased in the VPAtreated animal, such that both the area occupied by the positively stained cells and the intensity of the Tuj1 staining were significantly increased in the $\mathrm{CP}$ region (Figure $5 \mathrm{~A}$; upper right panel). The area occupied by the PCNA-positive cells and the intensity of PCNA staining, by contrast, were significantly reduced in the SVZ and IMZ areas in the VPA-treated animals (Figure $5 B$; middle right panel). BMP4 was significantly increased by VPA treatment (Figure 5A; compare lowest panels). In addition, the BMP4-positive cells were localized in both areas, that is, where Tuj1- and PCNA-positive cells resided. We also observed a significant increase in the level of Pan-Ras at the membrane areas of the neocortex in a VPA-administered
A

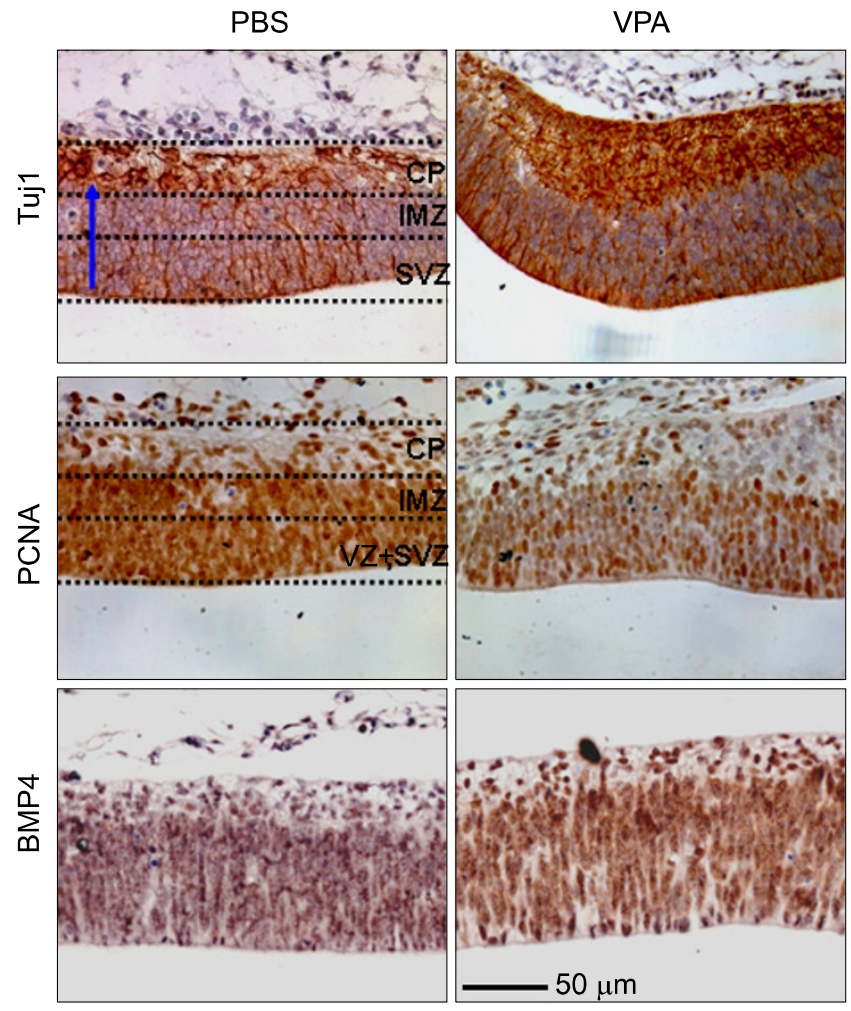

B
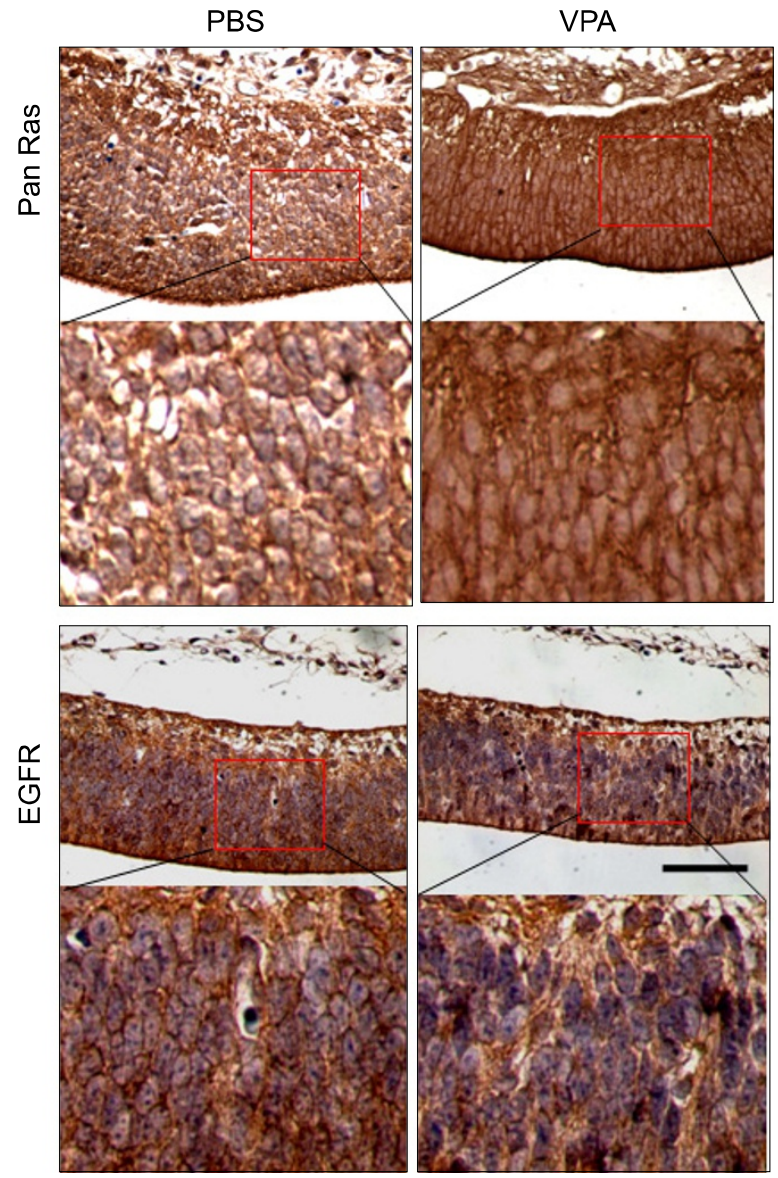

Figure 5. Effects of VPA on inductions of Tuj1 and PCNA and on expressions of BMP4, Ras, and EGFR in cerebral cortex of developing rat brain. The rats on day 13.5 of gestation were intravenously injected with PBS or $200 \mathrm{mg} / \mathrm{kg}$ VPA in PBS every $24 \mathrm{~h}$ for 2 days before sacrifice. Immunohistochemical analyses of coronal sections of the embryonic E15.5 rat brain were performed with anti-Tuj1, -PCNA, anti-BMP4 (A), -Pan-Ras or -EGFR antibody (B), followed by DAB staining. The nuclei were stained using Mayer's hematoxylin. The dashed lines divide the cerebral cortex into the three layers: the cortical plate (CP), the intermediate zone (IMZ), the subventricular zone (SVZ), and the ventricular zone (VZ) above lateral ventricle (LV). The blue arrows indicate the migration directions of the differentiating cells. Scale bar: $50 \mu \mathrm{m}$. 
animal, compared with a PBS-treated one (Figure $5 \mathrm{~B}$; compare upper panels; magnified images are shown below). The EGFR in the membrane areas, of course, was reduced by VPA treatment, as observed of the NSC culture (Figure 5B; magnified images are shown below). Thus, our in vivo results showing activation of Tuj1 through the axis of differentiation of NSCs agree with the in vitro results for the NSC culture.

\section{Discussion}

Identification and characterization of the mechanism of the differentiation of stem cells is a first step toward application of stem cell technologies to regenerative medicine. The ERK pathway plays role in the differentiation of various cell types including stem cells as well as its well known function in cell growth (Li et al., 2006; Sun et al., 2006). The ERK pathway is known to be involved in both positive and negative regulations of differentiations, depending on extracellular stimuli (Woessmann et al., 2004; Kunath et al., 2007). In this study, we identified a role of the ERK pathway in the neuronal differentiation of NSCs by BMP4, a soluble secretory ligand of the TGF $\beta$ superfamily. BMP4 induced neuronal differentiation of NSCs via activation of the Ras-ERK pathway, as indicated by blockage of Tuj 1 induction by dnRas. The activation of the Ras-ERK pathway by BMP4 occurred by a novel mechanism involving regulation of the Ras protein level. The EGFR, an upstream receptor of the Ras-ERK pathway, was significantly suppressed, as previously observed by others (Lillien and Raphael, 2000; Garcion et al., 2004), the regulation occurring at the transcription level. This result indicates that Ras reduction by BMP4 can be acquired via an EGFR-independent route. The destabilization of Ras protein could occur through Wnt/ $\beta$-catenin-mediated signaling or by direct signaling via $\beta$-catenin (Park et al., 2006; Jeon et al., 2007). Therefore, the observed Ras level increase by BMP4 is supported by BMP4's being a target for Wnt/ $\beta$-catenin signaling (Baker et al., 1999). Thus it is also possible that BMP4 could be a mediator involved in regulation of Ras protein stability by Wnt/ $\beta$-catenin signaling. VPA is an inhibitor of GSK3 $\beta$ (Chen et al., 1999; Grimes and Jope, 2001), therefore, the BMP4 induction by VPA occur via $\beta$-catenin stabilization through the inhibition of the activity of GSK3 3 . All of the effects of BMP4, neuronal differentiation, Ras level increases, ERK activation, EGFR supression, and Tuj1 induction, also were manifested as a result of NSC treatment with VPA. The roles of VPA, such as induction of
BMP4, inhibition of proliferation, up-regulation of Ras, and down-regulation of EGFR, were further confirmed by in vivo analyses involving the application of VPA to a developing E13.5 rat embryo. The effects of VPA were blocked by co-treatment of the BMP4 antagonist noggin. These results show that the VPA effects can be produced via induction of BMP4, and they indicate, further, that VPA is a potential replacement for BMP4 in therapeutic applications.

Development of small molecules that mimic the effect of therapeutic proteins is integral to clinical application and commercialization. Here, we identified the BMP4-mimicking effects of VPA, which could lead to usage of VPA in the control of BMP4activation-related diseases as well for its identified pharmacological effects such as in treatment of epilepsy (Perucca, 2002). VPA is more commonly known as an inhibitor of histone deacetylases (HDAC) (Hsieh et al., 2004), and has various pharmacological effects including brain tumor suppression, neuroprotection, peripheral nerve injury enhancement, cell cycle arrest, apoptosis, terminal differentiation of neoplastic cells, antiepileptic properties, as well as antineoplastic and antiangiogenesis effects (Cui et al., 2003). In a recent study, BMP4 also was identified as a potential inhibitor of the growth of brain-tumor-initiating cells (Piccirillo et al., 2006). The potential roles of VPA as a replacement for BMP4 need to be investigated by means of further characterization of its functional mechanisms.

\section{Methods}

\section{Animals and VPA treatment}

SD Rats (250-280 mg) were purchased from KOATECH (Pyongtaek, Korea). All animal procedures were approved by the Institutional Review Board of Severance Hospital, Yonsei University College of Medicine. Rats were housed in filter-topped shoebox cages with a computerized environmental control system from MJ LTD (Seoul, Korea). The rats were allowed free access to water and given a standard maintenance diet from Dae Han Bio Link (Daejeon, Korea), and were maintained at $26.5^{\circ} \mathrm{C}$ with a relative humidity of $40-70 \%$. Beginning on embryonic day 13.5 (E13.5) of gestation, the rats were intravenously injected with $200 \mathrm{mg} / \mathrm{kg}$ VPA (Acros Organics, Geel, Belgium) (every $24 \mathrm{~h}$ for 2 days), and were given water containing $15 \mathrm{~g} / \mathrm{l}$ VPA.

\section{Primary cerebral cortical stem cell culture and VPA treatment}

Neural stem cells were isolated from the cerebral cortex of 
E14 Sprague-Dawley (SD) rats, as described previously (Enarsson et al., 2002). The isolated cortical cells (passage 0 ) were seeded on dishes coated with $15 \mu \mathrm{g} / \mathrm{ml}$ poly-Lornithine and $10 \mu \mathrm{g} / \mathrm{ml}$ fibronectin (Sigma-Aldrich, St. Louis, $\mathrm{MO})$ and cultured in a humidified atmosphere of $95 \%$ air-5\% $\mathrm{CO}_{2}$ at $37^{\circ} \mathrm{C}$ in N2 medium [DMEM/F12 (1:1) (Gibco $\mathrm{BRL}$, Carlsbad, CA) medium containing $100 \mu \mathrm{M}$ putrescine, $30 \mathrm{nM}$ selenite, $20 \mathrm{nM}$ progesterone, $1.55 \mathrm{mg} / \mathrm{ml} \mathrm{D-(+)-}$ glucose, $25 \mu \mathrm{g} / \mathrm{ml}$ insulin, $0.1 \mu \mathrm{g} / \mathrm{ml}$ apo-transferrin (Sigma-Aldrich), $0.5 \mathrm{mM}$ glutamax, penicillin $(100 \mathrm{IU} / \mathrm{ml})$ and streptomycin $(100 \mu \mathrm{g} / \mathrm{ml})$ with bFGF $(10 \mathrm{ng} / \mathrm{ml})$ (Invitrogen, Carlsbad, CA)]. The NSCs of the passage 0 were plated in $60 \mathrm{~mm}$ culture dishes at a density of $4.5 \times 10^{5}$ and expanded in N2 medium with bFGF (10 $\mathrm{ng} / \mathrm{ml})$ for $48 \mathrm{~h}$. The cultured cells were photographed using an ECLIPSE TE2000-U Fluorescent microscope (Nikon, Tokyo, Japan) equipped with a digital CCD camera from Diagnostic Instruments, Inc. (Sterling Heights, MI).

\section{Immunoblot analysis}

The cells were lysed in $1 \times$ Laemmli lysis buffer $(2.4 \mathrm{M}$ glycerol, $0.14 \mathrm{M}$ Tris [pH 6.8], 0.21 M SDS, $0.3 \mathrm{mM}$ bromophenol blue) on ice prior to centrifugation at 15,000 $\times g$ for $30 \mathrm{~min}$ at $4^{\circ} \mathrm{C}$. The protein quantities were determined using the Bradford protein assay kit (Bio-Rad Laboratories, Inc., Hercules, CA), and were separated on $8-12 \%$ SDS-PAGE gels. After blocking in 5\% nonfat dry milk in TBS-Tween $20(0.1 \%, \mathrm{v} / \mathrm{v})$, the blots were incubated overnight at $4^{\circ} \mathrm{C}$ with primary antibodies. The primary antibodies used were EGFR, p-ERK (Cell signaling Biotechnology, Beverly, MA), PCNA, $\beta$ - catenin (Santa Cruz, CA), pan-Ras (Upstate Biotechnology, Lake Placid, NY), Tuj1 (Covence, Princeton, NJ), BMP4 (R\&D Systems, Minneapolis, MN), and $\beta$-actin (Abcam Inc., Cambridge, MA). HRP-conjugated anti-mouse (Bio-Rad Laboratories, Hercules, CA) or anti-rabbit secondary antibodies (Calbiochem, La Jolla, CA) was applied before detection by a luminescent image analyzer, LAS-3000 (Fujifirm, Tokyo, Japan).

\section{Immunocytochemistry and immunohistochemistry}

For the immunocytochemistry, NSCs were fixed in $4 \%$ paraformaldehyde (PFA) for $30 \mathrm{~min}$, rinsed with PBS, and rendered permeable with $0.2 \%$ Triton $\mathrm{X}-100$ in PBS for 20 min. Preparatory to bromodeoxyuridine (BrdU) labeling, the cells were incubated in $2 \mathrm{M} \mathrm{HCl}$ for 30 min and rinsed three times with PBS. The antibodies used were Tuj1, PCNA, BMP4, panRas, and EGFR. The cells were washed three times in PBS and incubated with Alexa Fluor 488- or Alexa Fluor 555-conjugated IgG secondary antibody (Molecular Probes, Carlsbad, CA) at room temperature for 45 $\mathrm{min}$. The cell nuclei were counterstained by incubating cells in $1 \mu \mathrm{g} / \mathrm{ml}$ 4'-6-diamidino-2-phenylindole (DAPI) (Boehringer Mannheim, Mannheim, Germany) for $10 \mathrm{~min}$ and extensively washed in distilled water. Fluorescent labeling was visualized on a Radiance 2100 multi-photon imaging system (Bio-Rad, Hertfordshire, UK) and an LSM510META (Carl Zeiss, Göttingen, Germany) at excitation wavelengths of $488 \mathrm{~nm}$ (Alexa Fluor 488), $543 \mathrm{~nm}$ (Alexa Fluor 555) and $405 \mathrm{~nm}$ (DAPI) respectively. Prior to histological analyses, embryo specimens were fixed in $4 \%$ paraformaldehyde (PFA) for $12 \mathrm{~h}$, rinsed with water, dehydrated by serial immersion in alcohol cleared in xylene, and embedded in paraffin. Tissue blocks were sectioned at 4-5 $\mu \mathrm{m}$ thicknesses using a RM2245 microtome from Leica Microsystems (Wetzlar, Germany).

The immunohistochemical analysis was performed using the UltraTek HRP kit (Scytek Laboratories Inc, West Logan, UT) and the ImmunoHisto Peroxidase Detection Kit from Pierce (Rockford, IL). Antigen retrieval was performed

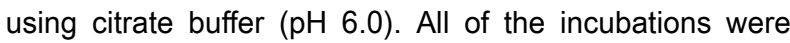
carried out in humid chambers. Diaminobenzidine (DAB)stained preparations were visualized using the Nikon ECLIPSE TE2000-U fluorescent microscope.

\section{Vector and siRNA}

Rat BMP4 (NM_012827) mRNA target sequences were designed using the siRNA template design tool (Ambion, Austin, TX). The BMP4 target sequences were 5'-GACAGATGCTAGTTTGATATT-3' (63-81) and 5'-ACACCAGACTAGTCCGTCATT-3' (605-623). The HA-BMP4-pcDNA3.0 vector was obtained from Dr. Dae-Won Kim of Yonsei University (Seoul, Korea).

\section{RT-PCR}

Total RNAs were prepared using TRIzol reagent (Invitrogen) according to the manufacturer's instructions. cDNA was synthesized in vitro using M-MLV reverse transcriptase (Invitrogen). PCRs were performed with Taq DNA polymerase at $94^{\circ} \mathrm{C}$ for $5 \mathrm{~min}$ followed by 35 cycles at $94^{\circ} \mathrm{C}$ for $30 \mathrm{~s}, 55^{\circ} \mathrm{C}$ for $1 \mathrm{~min}$, and $72^{\circ} \mathrm{C}$ for $1 \mathrm{~min}$ using a System 2700 (Applied Biosystems, Foster City, CA). The PCR products were electrophoresed on agarose gels and photographed using an LAS3000. The sequences of the primers used were as follows: rat HPRT upstream 5' CCTGCTGGATTACATTAAAGCGCT-3'; downstream 5'-AAACAACAACCTATACGGGAACTG-3'; rat BMP4 upstream 5'-AGAAATGGTGCCTGGACACCTCAT-3'; downstream 5'TGGTCCCGGTTGTACAGTCCTAAT-3'; rat EGFR upstream 5'-ACAACTGTGAAGTGGTCCT-3'; downstream 5'TACGCCTTGAATGTCCTT-3'.

\section{Acknowledgements}

This work was supported by a National Research Laboratory Grant from the Korea Science and Engineering Foundation (KOSEF) funded by the Ministry of Education, Science and Technology (MIST) of Korea (No. 200501564; 2006-02681; R112000078010020). Byoung-San 
Moon and Ju-Young Yoon were supported by a BK21 studentship from the Ministry of Education, Science and Technology (MIST).

\section{References}

Baker JC, Beddington RS, Harland RM. Wnt signaling in Xenopus embryos inhibits bmp4 expression and activates neural development. Genes Dev 1999;13:3149-59

Chen G, Huang LD, Jiang YM, Manji HK. The moodstabilizing agent valproate inhibits the activity of glycogen synthase kinase-3. J Neurochem 1999;72:1327-30

Cobb MH. MAP kinase pathways. Prog Biophys Mol Biol 1999;71:479-500

Cui SS, Yang CP, Bowen RC, Bai O, Li XM, Jiang W, Zhang $X$. Valproic acid enhances axonal regeneration and recovery of motor function after sciatic nerve axotomy in adult rats. Brain Res 2003:975:229-36

Enarsson M, Erlandsson A, Larsson H, Forsberg-Nilsson $\mathrm{K}$. Extracellular signal-regulated protein kinase signaling is uncoupled from initial differentiation of central nervous system stem cells to neurons. Mol Cancer Res 2002;1: 147-54

Furuta Y, Piston DW, Hogan BL. Bone morphogenetic proteins (BMPs) as regulators of dorsal forebrain development. Development 1997;124:2203-12

Gage FH. Mammalian neural stem cells. Science 2000;287: 1433-8

Garcion E, Halilagic A, Faissner A, ffrench-Constant C. Generation of an environmental niche for neural stem cell development by the extracellular matrix molecule tenascin C. Development 2004;131:3423-32

Goswami M, Uzgare AR, Sater AK. Regulation of MAP kinase by the BMP-4/TAK1 pathway in Xenopus ectoderm. Dev Biol 2001;236:259-70

Gould TD, Manji HK. The Wnt signaling pathway in bipolar disorder. Neuroscientist 2002;8:497-511

Gould TD, Chen G, Manji HK. In vivo evidence in the brain for lithium inhibition of glycogen synthase kinase-3. Neuropsychopharmacology 2004;29:32-8

Grimes CA, Jope RS. CREB DNA binding activity is inhibited by glycogen synthase kinase-3 beta and facilitated by lithium. J Neurochem 2001;78:1219-32

Gross RE, Mehler MF, Mabie PC, Zang Z, Santschi L, Kessler JA. Bone morphogenetic proteins promote astroglial lineage commitment by mammalian subventricular zone progenitor cells. Neuron 1996;17:595-606

He TC, Sparks AB, Rago C, Hermeking H, Zawel L, da Costa LT, Morin PJ, Vogelstein B, Kinzler KW. Identification of C-MYC as a target of the APC pathway. Science 1998; 281:1509-12

Hsieh J, Nakashima K, Kuwabara T, Mejia E, Gage FH. Histone deacetylase inhibition-mediated neuronal differentiation of multipotent adult neural progenitor cells. Proc Natl

\section{Acad Sci USA 2004;101:16659-64}

Jeon SH, Yoon JY, Park YN, Jeong WJ, Kim S, Jho EH, Surh YJ, Choi KY. Axin inhibits extracellular signal-regulated kinase pathway by Ras degradation via beta-catenin. J Biol Chem 2007;282:14482-92

Jung DS, Baek SY, Park KH, Chung YI, Kim HJ, Kim CD, Cho MK, Han ME, Park KP, Kim BS, Kim JB, Oh SO. Effects of retinoic acid on ischemic brain injury-induced neurogenesis. Exp Mol Med 2007;39:304-15

Kato T, Ohtani-Kaneko R, Ono K, Okado N, Shiga T. Developmental regulation of activated ERK expression in the spinal cord and dorsal root ganglion of the chick embryo. Neurosci Res 2005;52:11-9

Kim JS, Crooks H, Dracheva T, Nishanian TG, Singh B, Jen $\mathrm{J}$, Waldman T. Oncogenic beta-catenin is required for bone morphogenetic protein 4 expression in human cancer cells. Cancer Res 2002;62:2744-8

Kunath T, Saba-El-Leil MK, Almousailleakh M, Wray J, Meloche S, Smith A. FGF stimulation of the Erk1/2 signalling cascade triggers transition of pluripotent embryonic stem cells from self-renewal to lineage commitment. Development 2007;134:2895-902

Kuroda H, Fuentealba L, Ikeda A, Reversade B, De Robertis EM. Default neural induction: neuralization of dissociated Xenopus cells is mediated by Ras/MAPK activation. Genes Dev 2005;19:1022-7

Leng Y, Liang MH, Ren M, Marinova Z, Leeds P, Chuang DM. Synergistic neuroprotective effects of lithium and valproic acid or other histone deacetylase inhibitors in neurons: roles of glycogen synthase kinase-3 inhibition. J Neurosci 2008; 28:2576-88

Lewis TS, Shapiro PS, Ahn NG. Signal transduction through MAP kinase cascades. Adv Cancer Res 1998;74:49-139

Li W, Cogswell CA, LoTurco JJ. Neuronal differentiation of precursors in the neocortical ventricular zone is triggered by BMP. J Neurosci 1998;18:8853-62

$\mathrm{Li}$ Z, Theus MH, Wei L. Role of ERK 1/2 signaling in neuronal differentiation of cultured embryonic stem cells. Develop Growth Diff 2006;48:513-23.

Lillien L, Raphael H. BMP and FGF regulate the development of EGF-responsive neural progenitor cells. Development 2000;127:4993-5005

Lin SY, Chen CL, Wu YL, Yang YC, Hwu YM. Ratio of Wnt3a to BMP4 doses is critical to their synergistic effects on proliferation of differentiating mouse embryonic stem cells. Cell Prolif 2008;41:492-505

Mohan RR, Kim WJ, Chen L, Wilson SE. Bone morphogenic proteins 2 and 4 and their receptors in the adult human cornea. Invest Ophthalmol Vis Sci 1998;39:2626-36

Molne M, Studer L, Tabar V, Ting YT, Eiden MV, McKay RD. Early cortical precursors do not undergo LIF-mediated astrocytic differentiation. J Neurosci Res 2000;59:301-11

Mujtaba T, Mayer-Proschel M, Rao MS. A common neural progenitor for the CNS and PNS. Dev Biol 1998;200:1-15 
Panchision DM, Pickel JM, Studer L, Lee SH, Turner PA, Hazel TG, McKay RD. Sequential actions of BMP receptors control neural precursor cell production and fate. Genes Dev 2001;15:2094-110

Panchision DM, McKay RD. The control of neural stem cells by morphogenic signals. Curr Opin Genet Dev 2002;12: 478-87

Park KS, Jeon SH, Kim SE, Bahk YY, Holmen SL, Williams BO, Chung KC, Surh YJ, Choi KY. APC inhibits ERK pathway activation and cellular proliferation induced by RAS. J Cell Sci 2006;119:819-27

Perucca E. Pharmacological and therapeutic properties of valproate: a summary after 35 years of clinical experience. CNS Drugs 2002;16:695-714

Piccirillo SG, Reynolds BA, Zanetti N, Lamorte G, Binda E, Broggi G, Brem H, Olivi A, Dimeco F, Vescovi AL. Bone morphogenetic proteins inhibit the tumorigenic potential of human brain tumour-initiating cells. Nature 2006;444:761-5

Sun P, Watanabe H, Takano K, Yokoyama T, Fujisawa JI, Endo T. Sustained activation of M-Ras induced by nerve growth factor is essential for neuronal differentiation of PC12 cells. Genes to Cells 2006;11:1097-113
Tanriover G, Demir N, Pestereli E, Demir R, Kayisli UA. PTEN-mediated Akt activation in human neocortex during prenatal development. Histochem Cell Biol 2005;123:393406

Varley JE, Maxwell GD. BMP-2 and BMP-4, but not BMP-6, increase the number of adrenergic cells which develop in quail trunk neural crest cultures. Exp Neurol 1996;140:84-94

Vaudry D, Stork PJ, Lazarovici P, Eiden LE. Signaling pathways for PC12 cell differentiation: making the right connections. Science 2002;296:1648-9

Woessmann W, Zwanzger D, Borkhardt A. ERK signaling pathway is differentially involved in erythroid differentiation of K562 cells depending on time and the inducing agent. Cell Biol Int 2004;28:403-10

Xu RH, Chen X, Li DS, Li R, Addicks GC, Glennon C, Zwaka TP, Thomson JA. BMP4 initiates human embryonic stem cell differentiation to trophoblast. Nat Biotechnol 2002;20: $1261-4$

Zhou Q, Heinke J, Vargas A, Winnik S, Krauss T, Bode C, Patterson C, Moser M. ERK signaling is a central regulator for BMP-4 dependent capillary sprouting. Cardiovasc Res 2007;76:390-9 